\title{
Article
}

\section{The body in balance: Humoral medicines in practice}

Tobyn, Graeme William

Available at http://clok.uclan.ac.uk/17157/

Tobyn, Graeme William ORCID: 0000-0002-1415-9421 (2015) The body in balance: Humoral medicines in practice. Journal of Herbal Medicine, 5 (2). pp. 128-129. ISSN 2210-8033

It is advisable to refer to the publisher's version if you intend to cite from the work. http://dx.doi.org/10.1016/j.hermed.2015.04.001

For more information about UCLan's research in this area go to http://www.uclan.ac.uk/researchgroups/ and search for <name of research Group>.

For information about Research generally at UCLan please go to http://www.uclan.ac.uk/research/

All outputs in CLoK are protected by Intellectual Property Rights law, including Copyright law. Copyright, IPR and Moral Rights for the works on this site are retained by the individual authors and/or other copyright owners. Terms and conditions for use of this material are defined in the policies page.

\section{CLoK}

Central Lancashire online Knowledge www.clok.uclan.ac.uk

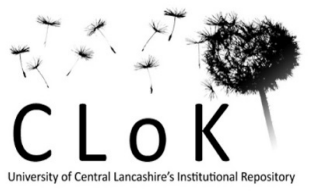




\title{
The Body in Balance: Humoral Medicines in Practice
}

\author{
Edited by Peregrine Horden and Elisabeth Hsu. \\ Epistemologies of Healing vol.13. Oxford: Berghahn Books, \\ 2013. hardback pp.288, ISBN: 978-0-85745-982-4. £75 \\ (paperback edition released 9/2/15 ISBN: 978-1-78238-907-1 \\ $£ 22$ )
}

This collection of essays on practice within traditional medicine systems in different cultures and continents, bracketed by unifying introductory and concluding chapters, is noted among its testimonies as a unique collection that provides an extremely good basis for comparative studies of global healing practices, a point I can wholeheartedly agree with. Nearly all of the contributors are professors in their fields - anthropology, history, classics, nutrition - and they investigate the notion of balance and how this is to be maintained or restored by medical practice, both in the 'Great Traditions' of the East (Chinese medicine, Ayurveda) and the Greco-Arabic tradition of HippocraticGalenic medicine and Yunani Tibb, and in Tibetan medicine and Mesoamerican and East African healing practices. The ensuing rich discussions of herbal and shamanic practices present a range of cultural constructs, relate some of the healing foods and herbs employed and offer analysis of the underlying epistemologies of their healing systems. The introduction to this set of essays, which sets out the problems in trying to navigate through the world's major systems of thought about the nature of health and the causes of disease, and its concluding chapter, which successfully links together the themes and findings of the studies, mount a substantial and thoughtprovoking series of challenges to the established explanatory frameworks of medical historians and anthropologists.

The title of the book communicates its central issue: how is balance, which denotes health, defined and characterised in the different medical systems, by whom and in what circumstances? And are the theories of different humoral medicines, for "'humoral medicine in practice' is 'the body in balance"" (p.18), important in word or deed in actual encounters between sufferer and healer? The opening essay by Helen King on 'Female fluids in the Hippocratic corpus' questions the role of even the classical humours in so-called humoral practice. King shows that the four-humour model that Galen later rooted at the base of his system was a rarity in Hippocratic medicine: humours as fluids were only one aspect of disease in the writings and were not a key to unlock all diagnostic problems. Emilie Savage-Smith points out that the term 'humoral pathology' was not coined in English until 1793 and, while diagnosis and causality in Medieval Islamic medicine was certainly based on the humours, herbal prescribing was shaped rather by the notion of balance of the primary qualities hot/cold and dry/moist. Peter Murray Jones carries the point further in the late Medieval period when he looks at the tensions between prescriptions rationally based on the complexio of the patient and those experimenta or remedies not designed according to theory to rebalance the sick body that nevertheless were effective treatments. Antidotes to the plague, thought to combat poison in the body, is the classic example of prescribing against the disease, or what Jones calls 'medical instrumentalism'. 
Moving from one tradition to consider theory and practice in other cultures, the editors firmly reject the lumping together of Hippocratic, Ayurvedic and Chinese medicines and deconstruct the concept of 'Great Traditions' as 'a fabrication of anthropologists' and the rhetoric of the 'scholarly medical traditions' as "an integral part of a symbolic language of class and status" (p.262). The major medical systems, configured as grounded in inductive and synthetic thought and emphasising microcosm-macrocosm analogies, are, when their practices are closely examined, very diverse as to the concept of 'balance' (its restoration the theoretical object of therapy), with "a range of balances, equivalences, congruencies and proportional relationships...in play across the history and ethnography of world medicine" (p.18).

Ellen Messer shows that recent research by Mexican ethnographers substantially undermines the older claim from US anthropologists that the hot/cold classification of herbs, foods and illnesses of Latin American health and healing cultures is a simplified version of European humoralism introduced by the Spanish. She argues that the hot/cold pairing is just one of the paired opposites that organise a Latin American cosmology with elemental, magical and supernatural worlds in which the goal of healing is the restoration of a dynamic balance of heat indicative of healthy soul substance. Yet even this balance is conditional on circumstances, a continuing moving target in life-cycles, wherein different needs apply to the pregnant woman or the mature adult, the victim of spiritual attack or the user of a biomedical drug: each tries to evaluate the imbalance and the remedy needed to restore equilibrium according to their own judgment within their shared world-view. On the other hand, Patrizia Bassini in her study of Tibetan medicine, the earliest written texts of which date from the seventh century CE and reflect the profound influence of Indian and Chinese medical traditions, asks if its concept of harmony is in any way relevant in the divine landscape of Qinghai, where the people leave off seeking a state of equilibrium with the surrounding landscape in favour of conducting endless numbers of rituals to try to restore order by warding off harm from evil forces. Analysing the notion of balance through three levels - the paradigmatic (descriptions of a balanced lifestyle), the illness narratives of the people and their ritual practices - Bassini shows that diseases are believed to result from bad action arising from desire, anger or ignorance and, even if these can be theoretically matched to humoral imbalances of Wind, Bile and Phlegm respectively, to be corrected by moral action through religious practices.

Moral transgressions are important too in David Parkin's study of health and wellbeing among one Bantu-speaking people living across different socio-political systems in East Africa. Sickness or misfortune requires a collective response and the reinstatement of a social morality that maintains the space for a path of moderation between extremes. Healers demonstrate a flexibility of interpretation and an experimental approach to finding solutions, best understood through individual examples because this is an oral healing culture not codified and thus fixed in writings, in which medico-metaphysical idioms of straightening and unblocking, and more familiar notions of cooling and cleansing in relation to a hot/cold polarity are invoked against entanglement in extremes to effect a restoration of balance. Parkin argues persuasively to free these practices from Westerners' notions that African healing is determined by an eco-cosmology, a necessary intertwining of the material 
and the spiritual, with which it can be distinguished from Euro-American medicine and the great written healing traditions.

A great strength of the book is the mastery of a wide range of current sources that underpin the scholarship of the contributors and especially the careful analysis of the editors. I particularly liked Elisabeth Hsu's examination of correlative thinking, an intrinsic aspect of scholarly medical traditions which are exemplified by microcosmmacrocosm analogies and are "typical of a style of cognition, wedged between what they call magical and causal thinking" (p.264). One of the key messages of the book is that healers are not always interested in theoretical humoral correlations and learned medical practice can substantially be a kaleidoscopic assemblage of interventions. Equally, an insistence on similarities in medical reasoning between the major medical systems of East and West promoted the notion of epistemological continuities when a focus on practice, previously rather neglected in favour of discussions on medical theory but now offered here, highlights fundamental cultural differences. It is not just the different numerologies of four humours, three doshas and five agents (wu xing) since these actually reflect attention to living in accord with the seasons as experienced within those cultures and places, and seasonally appropriate conduct has a shared ontological primacy between different traditions. There are also different socio-political influences within a given tradition on the moral dimension of the balance that is health. Hsu in her own study shows that the correlation of emotions with organs in Chinese medicine is not evidence of its holistic outlook and its correlative thinking concerning the somatisation of affect, but originates in the medicalisation of emotions such as anger that were deemed unacceptable in the last three centuries BCE when China was unifying and an Imperial bureaucracy was being formed.

The themes and discussions in the book were both challenging and stimulating. I could find little to fault: the characterisation of European astro-medical homologies of body and cosmos contrasted with the triad in the microcosm-macrocosm analogy within Chinese medicine of the person, society and the universe for me fails to recognise the healing substance itself as a third, intermediary factor of Western NeoPlatonic correspondences. I also missed the significance of "the appreciation of taste in medical practice", which I took to mean either the tastes and tasting of herbs or the taste of pathological humours rising to the mouth, as "an alternative explanation for the apparent pervasiveness of correlative thinking" (pp.263-4), since to my mind the organoleptic appreciation of herbal medicines offers a different dimension of meaning to the example of a tactile body technique discussed here, namely pulse diagnostics. The most explicit chapter on the formulation and preparation of a herbal remedy in this collection is Francis Zimmermann's exploration of the Ayurvedic diagnosis of arthropathies as Wind diseases and their treatment in Kerala with the locally sourced and prepared 'oil of Dhanvantari'. Zimmermann shows both the polysemic (having multiple meanings) quality of terms used by an Ayurvedic physician such as 'Wind diseases' and the mapping of the local ecology and its medicinal plants onto the human body instead of thinking anatomically. For this reader, these are lines of enquiry to be taken up in future research based on the strong foundations provided by this comparative study. 
The book is scholarly, well written and supported by references and bibliography. It draws mainly on medical anthropology and history of medicine for its lineage and is a solid contribution to the scholarship in these fields. Its range of comparative exploration and analysis is fresh and exciting, its identification and definitions of the concepts found to be shared across this range are clearly explained and should be broadly acknowledged and further explored in current debates on health and healing practices. Students and practitioners of health professions conventional and alternative who are interested in the global picture of healing and the dynamics of their practice that are shared across cultures will benefit from reading this book.

Graeme Tobyn is a senior lecturer, author of Culpeper's Medicine (1997/2014) and co-author of The Western Herbal Tradition (2011), and a practising medical herbalist for 25 years.

Graeme Tobyn

School of Health, University of Central Lancashire, United Kingdom

Email address: gwtobyn@uclan.ac.uk 